\title{
Comparison of Screening for Gestational Diabetes Mellitusby IADPSG andDIPSI Guidelines: Importance of Fasting Blood Glucose Value in Its Diagnosis and Management
}

\author{
Mitra Sujoy ${ }^{1}$, Rao PS $^{1}$, Mukhopadhyay I ${ }^{1}$, Prajwal $^{1}$ \\ ${ }^{1}$ Department ofObstetrics andGynaecology, Command Hospital, Bangalore, India
}

\begin{abstract}
Introduction: Gestational Diabetes Mellitus (GDM) is a common medical disorder complicating pregnancy. Two popular recommendations for screening for GDM in India are The Diabetes in Pregnancy Study Group of India (DIPSI) guidelines and the International Association of Diabetes and Pregnancy Study Groups (IADPSG) criteria. This study aims to compare the diagnostic rates of GDM by both these criteria and assess the severity of GDM in patients diagnosed by fasting value vs. non-fasting value.

Methods: A total of 1,470 pregnant women attending antenatal clinic at a tertiary care Armed Forces Hospital underwent a 75-g OGTT in fasting state. Venous plasma glucose was measured, and GDM was diagnosed using both DIPSI and IADPSG criteria. Severity of GDM in these patients was assessed by whether patients were treated with medical nutrition therapy (MNT) alone or required pharmacotherapy.

Results: Of the 1470 women screened, IADPSG criteria identified $176(11.97 \%)$ to have GDM vs.58 (3.94\%) by DIPSI criteria. 124 (8.43\%) patients were diagnosed by fasting values of which $27.4 \%$ needed pharmacotherapy vs.58 (3.54\%) diagnosed by non-fasting values of which $57.69 \%$ needed pharmacotherapy. Conclusions: The DIPSI criteria has low diagnostic rate as compared to IADPSG criteria because it ignores the Fasting Blood Glucose (FBG) levels. Patients diagnosed as GDM by fasting value have similar severity of GDM as those diagnosed by non-fasting values.
\end{abstract}

Keywords: GDM, DIPSI, IADPSG, Severity of GDM, Fasting Blood Glucose

\section{Introduction}

Gestational diabetes (GDM) is defined as carbohydrate intolerance of variable severity with onset or first recognition during pregnancy [1]. Women with a history of GDM are at increased risk of future diabetes; predominately type 2 .Theirchildren are at increased risk of obesity, glucose intolerance, and diabetes in late adolescence and young adulthood [2], and thus, GDM offers an important opportunity for diagnosis and implementation of clinical strategies for diabetes prevention. The prevalence of GDM varies widely based on the diagnostic criteria used and the ethnic group studied [3].In the Indian context, screening is essential in all pregnant women as the Indian women have eleven fold increased risk of developing glucose intolerance during pregnancy compared to Caucasian women [3]. Among ethnic groups in south Asian countries, the Indian women have highest frequency of GDM. Recent data shows $16.55 \%$ prevalence of GDM in India [4].

In 1999, the World Health Organization (WHO) introduced criteria for diagnosis of GDM on the basis of a 2-h venous plasma glucose (VPG) cut-off value of $140 \mathrm{mg} / \mathrm{dl}(7.8 \mathrm{mmol} / \mathrm{l})$, after the administration of $75 \mathrm{~g}$ of glucose [5]. The WHO 1999 criteria have become popular, particularly in developing countries, because it is simpler than the two-step procedure [6]. In 2010, The Hyperglycemia and Adverse Pregnancy Outcome (HAPO) study [7], a large-scale (25,000 pregnant women) multinational cohort study, demonstrated that risk of adverse maternal, fetal, and neonatal outcomes continuously increased as a function of maternal glycemia at 2428 weeks, even within ranges previously considered normal for pregnancy. The IADPSG defined diagnostic cut points for GDM as the average glucose values (fasting, 1-h, and 2-h PG) in the HAPO study at which odds for adverse outcomes reached 1.75 times the estimated odds of these outcomes at the mean glucose levels of the study population. Based on the HAPO study, IADPSG proposed a new set of criteria which has since been adopted in many countries. Recently, the WHO has also adopted the IADPSG criteria [8].In the 2011 Standards of Care [9], the ADA for the first time recommended that all pregnant women not known to have prior diabetes undergo a 75-g OGTT at 24-28 weeks of gestation, based on the recommendation of IADPSG [10]. Thus, there is still no consensus on the screening and diagnostic criteria of GDM in India.

\section{Materials And Methods}

This is a retrospective study conducted from January 2015 to June 2016 at Command Hospital, Air Force, Bangalore. Data of the patients who delivered at the hospital were collected and studied. All pregnant women with estimated gestational age between 24th and 28th weeks attending ANC clinic during the study 
period were included in the study.IADPSG and DIPSI criteria were used for the diagnosis of GDM. Women who were known diabetics, or who were suffering from any chronic illness (CRF, autoimmune disorder etc.) were excluded from the study. All these women were subjected to $75 \mathrm{gm}$ OGTT between 24 to 28 weeks of gestation as per IADPSG guidelinesand data was analysed as per both IADPSG (use of 2 hour $75 \mathrm{~g}$ OGTT, any one deranged value of fasting plasma glucose $\geq 92$, 1hour $\geq 180$ and 2 hour $\geq 153$ as diagnosis of GDM) and DIPSI (one step procedure, between 24-28 weeks, diagnostic criteria being 2 hour plasma glucose is $\geq 140$ $\mathrm{mg} / \mathrm{dl}$ ) guidelines.

These patients diagnosed as GDM were further followed up and divided into two categories based on their response to treatment, that is, MNT alone or requirement of further pharmacotherapy (OHA/ Insulin). Those requiring additional pharmacotherapy were considered to have relatively more severe GDM.

\section{Observations and results}

A total of 1470patients who fulfilled the inclusion criteria were selected for the study.

The total number of patients diagnosed as GDM as per IADPSG and DIPSI criteria is shown in Table 1.

Number of patients diagnosed as GDM as per IADPSG and DIPSI criteria (Table 1)

\begin{tabular}{|c|c|c|}
\hline Total number of patients (n) & $\begin{array}{c}\text { Total number of patients } \\
\text { diagnosed by IADPSG }\end{array}$ & $\begin{array}{c}\text { Total number of patients diagnosed by } \\
\text { DIPSI }\end{array}$ \\
\hline 1470 & $176(11.97 \%)$ & $58(3.94 \%)$ \\
\hline
\end{tabular}

The difference between the diagnostic rates of IADPSG and DIPSI was significant at $\mathrm{p}<.01$.

The total number of patients diagnosed as GDM by both IADPSG and DIPSI criteria was only $2.7 \%$ as shown in Table 2.

Number of patients diagnosed as GDM by both IADPSG and DIPSI criteria (Table 2)
\begin{tabular}{|l|c|c|}
\hline & No. of cases & Percentage \\
\hline $\begin{array}{l}\text { Total number of patients diagnosed to be GDM } \\
\text { based on both IADPSG and DIPSI criteria }\end{array}$ & 40 & $2.7 \%$ \\
\hline
\end{tabular}

Among the cases diagnosed by IADPSG, we further sub divided the cases by fasting values and non-fasting values as shown in Table 3.

(Number of patients diagnosed to be GDM based on various abnormal values Table 3)

\begin{tabular}{|l|l|c|c|}
\hline & $\begin{array}{l}\text { Total number of patients diagnosed to be GDM based on } \\
\text { abnormal }\end{array}$ & No. of cases & Percentage \\
\hline 1. & Fasting value $(\geq 92 \mathrm{mg} / \mathrm{dL})$ alone & 124 & $8.43 \%$ \\
\hline 2. & 1 hr alone & 04 & $0.27 \%$ \\
\hline 3. & 1hour and 2 hour values & 07 & $0.47 \%$ \\
\hline 4. & All three values & 20 & $1.36 \%$ \\
\hline 5. & Fasting and 1hour values & 14 & $0.95 \%$ \\
\hline 6. & fasting and 2 hour values & 03 & $0.20 \%$ \\
\hline 7. & 2 hour values $\geq 153 \mathrm{mg} / \mathrm{dL}$ alone & 04 & $0.27 \%$ \\
\hline
\end{tabular}

Maximum number of cases of GDM $(8.43 \%)$ was detected by fasting values alone. Non fasting values were able to diagnose only $3.4 \%$ of cases. This was also significant at $p<.01$.

The response to therapy among the various sub groups was further analysed and divided into whether treated by MNT alone or requiring pharmacotherapy (OHA/ Insulin) as shown in Table 4.

Response to therapy among the various sub groups (Table 4)

\begin{tabular}{|l|l|c|c|l|}
\hline & \multicolumn{1}{|c|}{ Abnormal values } & Total & Treated by MNT & \multicolumn{1}{|c|}{$\begin{array}{c}\text { Treated by (OHA/ } \\
\text { Insulin) }\end{array}$} \\
\hline 1. & Fasting alone & 124 & 90 & $34(27.4 \%)$ \\
\hline 2. & $1 \mathrm{hr}$ alone & 04 & 1 & $03(75 \%)$ \\
\hline 3. & $1 \mathrm{hr}$ and $2 \mathrm{hr}$ & 07 & 01 & $06(85.7 \%)$ \\
\hline 4. & All three values & 20 & 9 & $11(55 \%)$ \\
\hline 5. & Fasting and $1 \mathrm{hr}$ & 14 & 08 & $06(42.85 \%)$ \\
\hline 6. & Fasting and $2 \mathrm{hr}$ & 03 & 02 & $01(33 \%)$ \\
\hline 7. & 2hr alone & 04 & 01 & $03(75 \%)$ \\
\hline & Total & 176 & $112(63.63 \%)$ & $64(36.36 \%)$ \\
\hline
\end{tabular}


Out of the patients diagnosed as GDM by fasting value alone, $27.4 \%$ required pharmacotherapy. In contrast, $57.69 \%$ patients diagnosed GDM by non-fasting values required pharmacotherapy. However, this difference was not significant.

\section{Discussion}

Glucose intolerance during pregnancy can be of varying severity. Early diagnosis, adequate treatment and follow-up are vital in successfully managing the patients as GDM is associated with high incidence of perinatal mortality and morbidity. In our study $11.97 \%$ were diagnosed as GDM as per IADPSG criteria and $3.94 \%$ as per DIPSI criteria. In the study conducted by Rajesh Rajput et al. at Post graduate institute of Medical Sciences , Haryana, the incidence was $7.1 \%$ as per ADA criteria ( 2 or more values required) but if only fasting single value was used then incidence was 9.06\% (55/607)[11]. The study conducted by a Kalra P et al. at Jodhpur, Rajasthanshowed that the incidence was $6.6 \%$ as per DIPSI criteria [12]. In the study conducted by Wahi P. et al. at Jammu and Kashmir showed that the incidence of GDM was $6.5 \%$ as per DIPSI criteria [13].

V.Balaji et al conducted a study at Government Maternity Hospital,Chennai,where the incidence of GDM was $18.9 \%$ as per WHO criteria [14].In a study by Nayak et al at Pondicherry Institute of Medical Sciences,Pondicherry, the incidence of GDM was $27 \%$ as per IADPSG criteria and if only fasting value was used then incidence was $23 \%$ [15]. V Mohan et al compared DIPSI with IADPSG for diagnosis of GDM. They had incidence of $4.2 \%$ with DIPSI and $10.3 \%$ with IADPSG [16]. A comparison of these studies is shown in Table 5.

\begin{tabular}{|l|c|c|c|}
\hline \multicolumn{1}{|c|}{ Comparison of various studies (Table 5) } \\
\hline \multicolumn{1}{|c|}{ Study } & $\mathrm{n}$ & GDM diagnosed (\%) & $\begin{array}{c}\text { GDM diagnosed with } \\
\text { Fasting Value only (\%) }\end{array}$ \\
\hline $\begin{array}{l}\text { PK Nayak et al (IADPSG) } \\
\text { 2013 South India }\end{array}$ & 304 & $83 / 304(27 \%)$ & $72 / 304(23 \%)$ \\
\hline $\begin{array}{l}\text { V Balaji et al (DIPSI) 2011 } \\
\text { South India }\end{array}$ & 1463 & $13.4 \%$ & N/A \\
\hline $\begin{array}{l}\text { Wahi P et al (DIPSI) 2011 } \\
\text { North India }\end{array}$ & N/A & $6.94 \%$ & N/A \\
\hline $\begin{array}{l}\text { Kalra P (DIPSI) 2013 } \\
\text { North India }\end{array}$ & 500 & $6.6 \%$ & $55 / 607(9.06 \%)$ \\
\hline $\begin{array}{l}\text { Rajesh Rajput (ADA) } \\
\text { North India }\end{array}$ & 1031 & $\begin{array}{c}\text { DIPSI 44/1031 (4.2\%) } \\
\text { IADPSG 106/1031 (10.3\%) }\end{array}$ \\
\hline $\begin{array}{l}\text { V Mohan (DIPSI vs IADPSG) } \\
\text { 2014 South India }\end{array}$ & & \\
\hline
\end{tabular}

In our study, the total number of patients diagnosed to be GDM by IADPSGwas $11.97 \%$, which is comparable to the study by V Mohan et al [16]. By DIPSI criteria, using only the $2 \mathrm{hr}$ value, GDM was diagnosed in $3.94 \%$ cases. This is also comparable to other studies [12, 13, and 16]. The diagnostic rate of GDM based only on the fasting value was $8.43 \%$. This also correlates with the findings of other studies $[11,16]$. Our study shows thatFBG value has the highest diagnostic rate for GDM which is being completely ignored by DIPSI.We further assessed the severity of GDM by dividing the patients into two groups, one on MNT alone and the other requiring some form of pharmacotherapy. We found that $27.4 \%$ of patients diagnosed as GDM by fasting value needed pharmacotherapy while $57.69 \%$ of patients diagnosed by non-fasting value required pharmacotherapy. The difference in the use of pharmacotherapy in these two groups was not significant.

\section{Conclusion}

Our study is unique in that the patients included in the studywere from all parts of the country and not localised to one ethnicity or community. IADPSG criteria were able to diagnose GDM at comparable rates but DIPSI was not. We suggest that IADPSG criteria may be better suited for implementation pan India rather than those proposed by DIPSI.Our study concludes that (a) IADPSG criteria detects more number of GDM cases than DIPSI, (b) FBG value alone can diagnose $8.43 \%$ of GDM which is more than the number detected by $2 \mathrm{hr}$ value, and (c) the severity of GDM in patients diagnosed by fasting value is comparable to that with non-fasting values and cannot be ignored.

\section{References}

[1]. Committee on Obstetric practice .Committee opinion no. 504: screening and diagnosis of gestational diabetes mellitus. ObstetGyncol. 2011 Sep; 118(3):751-3.

[2]. American Diabetic Association. Gestational diabetes mellitus. Diabetes care 2005; v27suppl 1:S88-S90.

[3]. Seshiah V, Balaji V, Balaji MS, Paneerselvam A, Kapur A .Pregnancy and diabetes scenario around world: India. Int J Gynaecol Obstet.2009; 104:35-8.

[4]. Seshiah V,Balaji V, Madhuri S Balaji,Sanjeevi CB, Green A. Gestational Diabetes Mellitus in India. JAssoc Physic of INDIA 2004; $52: 707-11$ 
[5]. Alberti KG, Zimmet PZ (1998) Definition, diagnosis and classification of diabetes mellitus and its complications. Part 1: diagnosis and classification of diabetes mellitus provisional report of a WHO consultation. Diabet Med 15:539-553

[6]. Expert Committee on the Diagnosis and Classification of Diabetes Mellitus. (2002) American Diabetes Association: clinical practice recommendations 2002. Diabetes Care 25(Supp1 1): S1-S147.

[7]. Metzger BE, Lowe LP, Dyer AR, et al.; HAPO Study Cooperative Research Group. Hyperglycemia and adverse pregnancy outcomes. N Engl J Med 2008;358:1991-2002

[8]. Diagnostic criteria and classification of hyperglycemia first detected in pregnancy. World Health Organization 2013, p.63; WHO/NMH/MND/13.2 http://apps.who.int/iris/bitstream/10665/ 85975/1/WHO_NMH_MND_13.2_eng.pdf. Accessed on 25 July 2014

[9]. American Diabetes Association. Standards of medical care in diabetesd2011. Diabetes Care 2011;34(Suppl. 1):S11-S61

[10]. Metzger BE, Gabbe SG, Persson B, et al.; International Association of Diabetes and Pregnancy Study Groups Consensus Panel. International Association of Diabetes and Pregnancy Study Groups recommendations on the diagnosis and classification of hyperglycemia in pregnancy. Diabetes Care 2010; 33:676-682

[11]. Rajput R, Yadav Y, Nanda S, Rajput M. Prevalence of gestational diabetes mellitus \& associated risk factors at a tertiary care hospital in Haryana. The Indian journal of medical research. 2013 Apr; 137(4):728.

[12]. Kalra P, Kachhwaha CP, Singh HV. Prevalence, of gestational diabetes mellitus and its outcome in western Rajasthan. Indian journal of endocrinology and metabolism. 2013 Jul; 17(4):677.

[13]. Wahi P, Dogra V, Jandial K, Bhagat R, Gupta R, Gupta S, Wakhloo A, Singh J.Prevalence of gestational diabetes mellitus (GDM) and its outcomes in Jammu region. JAssoc Physicians India. 2011 Apr; 59(4):227-30.

[14]. Balaji V, Balaji M, Anjalakshi C, Cynthia A, Arthi T, Seshiah V. Diagnosis of gestational diabetes mellitus in Asian-Indian women. Indian journal of endocrinology and metabolism. $2011 \mathrm{Jul} ; 15(3): 187$.

[15]. [Nayak PK, Mitra S, Sahoo JP, Daniel M, Mathew A, Padma A. Feto-maternal outcomes in women with and without gestational diabetes mellitus according to the International Association of Diabetes and Pregnancy Study Groups (IADPSG) diagnostic criteria. Diabetes \& Metabolic Syndrome: Clinical Research \& Reviews. 2013 Dec 31;7(4):206-9.

[16]. V Mohan, MM Mahalakshmi, B Bhavadharini, K Maheshwari, G Kalayarasi, RM Anjana, M Deepa, R Unnikrishnan. Comparison of screening of gestational diabetes mellitus by oral glucose tolerance done in non-fasting (random) and fasting states. Acta Diabetol (2014) 51:1007-1013 